\title{
New Technology Acceptance in Europe and Arabic Cultures: Comparative Study
}

\author{
Abdullah Rashed and Henrique Santos \\ $R$ \& D Algoritmi Centre, University of Minho, \\ Guimarães, Portugal
}

\section{rashed@dsi.uminho.pt; hsantos@dsi.uminho.pt}

\begin{abstract}
Many of the empirical researches have been done in western society and fewer researches have been done in Asia societies, especially Arab culture, where values differ significantly. In this paper, we compare Yemen (from Asian Arab countries) with Portugal (from Western Europe) in terms of new technology acceptance, related to ATM machine authentication mechanisms. We distributed the same questionnaire at the same time. The results support the previous studies concerning the relation between perceive of ease to use and intention to use. However, perceived usefulness has not significant effect over intention to use. In addition results suggest that security issues should be embedded within any technology acceptance model. Portuguese citizens showed more receptive to new technologies. However, Yemenis are more sensible to perceived usefulness.
\end{abstract}

Keywords: technology acceptance, intention to use, culture, Technology Acceptance Model, information security

\section{Introduction}

Technologies are designed to make our life easier. However user culture affects the acceptance and the effective utilization of those technologies. One of the reasons is that security systems (safe utilization) depend largely on human misbehavior, and this depends largely on cultural aspects (Dhamija, 2000).

To illustrate the cultural differences, we use the example narrated by Yeo (2009): "In the United States, the owl is a symbol of knowledge but in Central America, the owl is a symbol of witchcraft and black magic".

Culture is an important topic of research for global information systems (Myers, 2002) and among other aspects its effects should be considered on user behavioral patterns (Triandis, 1994). Moreover, it has an impact on the externalities of person's personality, the life and the life satis-

Material published as part of this publication, either on-line or in print, is copyrighted by the Informing Science Institute. Permission to make digital or paper copy of part or all of these works for personal or classroom use is granted without fee provided that the copies are not made or distributed for profit or commercial advantage AND that copies 1) bear this notice in full and 2) give the full citation on the first page. It is permissible to abstract these works so long as credit is given. To copy in all other cases or to republish or to post on a server or to redistribute to lists requires specific permission and payment of a fee. Contact Publisher@InformingScience.org to request redistribution permission. faction (Genkova, 2009). National culture also plays a significant role on the relative levels of satisfaction and consensus across nations. To understand feelings and people behavior when faced with problems, we have to know the characteristics of their culture (Samarah, 2002). Culture is defined as the set of shared attitudes, values, goals, and prac- 
tices that characterizes an institution, organization or group (Belshek, 2006).

Over the past decade it is noticed an increasing interest of IS (information Systems) research literature over the impact of cultural differences on the development and use of information and communications technologies (Myers, 2002). Many of the empirical researches have been carried out in western society but fewer researches have been done in Asia especially in Arab society, where culture and values differ significantly from the West (Quaddus, 2002).

Concerning biometrics adoption for the mainstream of authentication technologies, user acceptance is not yet resolved (Coventry, 2004). Many people think that new technologies will be easily adopted (Tibenderana, 2008). However, some illustrative cases challenge that assumption as an example, the first mechanical cash issuer was deployed, but removed after six months due to the lack of customer acceptance (Rashed, 2010a). Therefore many studies have been carried out to discover the boundary of acceptance in different cultures especially the western culture. Arabic culture lacks these kinds of studies with few publications in this field.

TAM and other similar models are used to measure the technology acceptance level. It focuses on the perceived usefulness and ease of use to measure the intention to use the technology, as shown in figure 1.

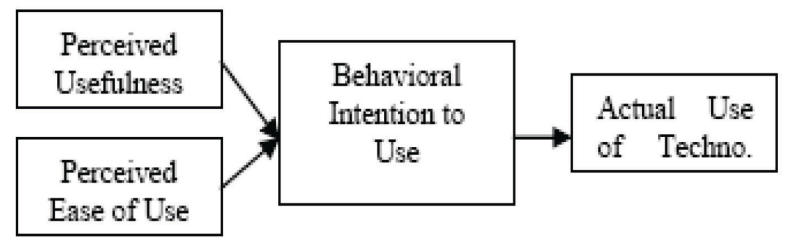

Figure 1: Technology Acceptance Model (Rashed, 2010b)

Many people who have access to technology find the experiences of their interactions difficult and unhappy due to the complexity of such technology. Within certain cultures this is enough to motivate resistance against change. But technology can be accepted using certain sociological and economic conditions (Beekhuyzen, 2005). This is the case with biometrics and its application to ATM.

Several biometric technologies have the characteristics needed for acceptance such as ease to use and usefulness that formulate the essential pillars of TAM (Rashed, 2010b). Concerning application domain, financial services are considered a key market for the biometrics industry (Coventry, 2004).

This paper validates and studies the acceptance of biometrics for ATM, in Europe and Arab countries. The study was supported by the responses to a questionnaire that we distributed via a web site. Participation was promoted by direct calls to university environments, and so the results are only valid within that population.

The rest of the paper is organised as follows. In section 2; we overview the previous studies as literature review and address the problem statement. In section 3 we demonstrate our methodology and present the discussion. We conclude and present future work in section 4.

\section{Literature Review}

Johnston classified the Internet as a virtual cultural region. He believed that with millions of users from all over the world, the Internet had developed its own culture. He also mapped the Internet culture using Hofstede's cultural (Rashed, 2010a).

Kersten et al. have produced a number of research reports on the influence of culture in international business negotiations. They also used Hofstede's cultural dimensions in their experiments. 
Their results confirmed that considerable cultural differences exist in both negotiation expectations and process (Kersten, 2011).

Quaddus et al. (2002) studied culture factors that affect the decisions among groups. They found that culture plays a significant role in decision making and the type of technologies used in decision support. They found that people with different values, preferences and beliefs, tend to view and use decision conference differently. They considered the issue of cultural differences as one potential source of explanation for differences in studies' results.

Myers criticized the concept of national culture and argued that it ignores the facts of history and has little explanatory power. He stated that IS researchers interested in conducting research on culture and globalization should adopt a more dynamic view of culture. He believed that the concept of national culture is problematic as there is no necessary alignment between culture and the nation-state. He stated that the nation-state is a relatively recent invention and had changed in its form and makeup. Moreover, he thought that many nation-states do not have a common basis in race, culture or language (Myers, 2002).

Mao extended a US based research model and applied it on Chinese culture. He compared his findings with the existing studies and found that his findings supported previous North America studies. Moreover, he confirmed the suitability and applicability of TAM, TRA (Theory of Reasoned Action) and IDT (Innovation Diffusion Theory) to study IT acceptance in Chinese culture (Rashed, 2010b).

Twati studied the cultural norms and beliefs within multi-national organizations in two regions: Arab countries on South Africa (Libya) and Arab countries on the Persian Gulf (Kuwait, Oman, Saudi Arabia, and United Arab Emirates). The study revealed that the two regions were not homogeneous. In addition, the study showed that age, gender, and education levels are factors contributing to the success of MIS (Management Information Systems) adoption in the two regions. Furthermore, the study showed differences in organizational cultures that impact upon MIS adoption in both regions. The Persian Gulf region was dominated by an adhocracy culture that values the adoption of MIS, whereas the North Africa region was dominated by the hierarchy culture type that favors a centralized management style, which impacts negatively MIS adoption. The Persian Gulf region did not show any significant effect on technology acceptance variables. However, in the North Africa region, technology acceptance played a vital role in MIS adoption (Twati, 2009).

Rose and Straub examined technology acceptance in five Arab cultures, three Asian (Jordan, Saudi Arabia, and Lebanon), two African countries (Egypt and the Sudan). They examined the ease of use and perceptions of usefulness. They studied the role of the two factors in actual usage decision and perception of usefulness (Rose, 1998). Their findings were consistent with the majority of TAM findings in the US.

Kripanont (2007) studied the Internet usage behaviour and behaviour intention to use. The survey included 927 academics within business schools in 20 public universities in Thailand and yielded 455 usable questionnaires, with a response rate of $49 \%$. The presented model is expected to have the power to explain and predict user behaviour in a Thai business school environment and might help practitioners to analyze the reasons for resistance toward the technology and also help them to take efficient measures to improve user acceptance and usage of the technology.

Ramayah et. al., studied and examined the intention to use an online bill payment among part time MBA students in Malaysia University of Sciences, Penang. They developed and modified the extended technology acceptance model and social cognitive theory, to identify factors that would determine and influence the intention to use an online bill payment system. They conducted a survey that involved 120 students. They found that perceived ease of use and 
perceived usefulness are the significant drivers of intention to use the online bill payment system. Furthermore, they found that subjective norm, image, result, demonstrability and perceived ease of use were the key determinants of perceived usefulness, whereas perceived risk was found to have a negative impact on usefulness level. Moreover, computer self-efficacy played a significant role in influencing the perceived ease of use of the online bill payment system (Ramayah, 2010).

Rashed et. al. wondered about using new biometric technologies (namely odour) as an authentication tool. They discussed its usage, advantages, disadvantages and user acceptance. They applied and tested TAM on the Arab culture and their findings were consistent with previous studies (Rashed, 2010b).

\section{Discussion}

The questionnaire used in this study included two parts. The first part looks for general information about the participants' background, like education and age. Respondents of the two groups (Portugal and Yemen) are young and educated. Figure 2 shows that the most frequent ages of both groups was within the interval [20-30], which represents young people. In both groups most of the respondents were IT connoisseurs. Most of the Portuguese respondents were master students whereas most Yemenis are at a BSc level.

\begin{tabular}{|c|c|r|r|}
\hline Variable & & Portuguese & \multicolumn{1}{|c|}{ Yemenis } \\
\hline \multirow{4}{*}{ Age } & $15-20$ & 0,17 & 0,11 \\
\cline { 2 - 4 } & $21-30$ & 0,46 & 0,69 \\
\cline { 2 - 4 } & $31-40$ & 0,35 & 0,17 \\
\cline { 2 - 4 } & More than 41 & 0,02 & 0,03 \\
\hline \multirow{4}{*}{ Specialization } & IT & 0,83 & 0,72 \\
\cline { 2 - 4 } & Engineering & 0,13 & 0,17 \\
\cline { 2 - 4 } & Medicine & 0,00 & 0,05 \\
\cline { 2 - 4 } & social sciences & 0,02 & 0,05 \\
\hline & Others & 0,02 & 0,00 \\
\hline
\end{tabular}

Figure 2: Sample profile

Figure 3 shows that $41 \%$ of the Yemenis respondent group and $36 \%$ of Portuguese respondent group think the idea of using odour in ATM would be easy to use (extremely or slight likely), whereas $35 \%$ of Portuguese group did not have an opinion. $25 \%$ of the Portuguese group reported that it would not be easy to use odour for authentication systems, against about $12 \%$ of the Yemenis that have the same opinion. 


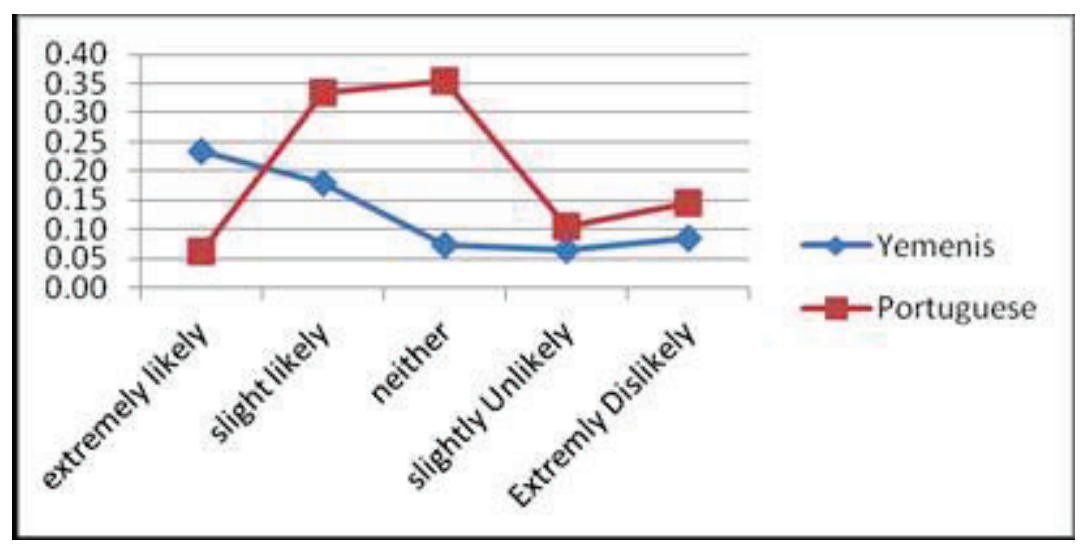

Figure 3: Perceived ease of use

Figure 4 shows that $46 \%$ of Yemenis and $26 \%$ of Portuguese thought that odour would improve the performance of their lives. $31 \%$ of Portuguese respondents did not think that odour would improve their lives performance. However, $43 \%$ of Yemenis and $40 \%$ Portuguese respondents did not have an opinion.

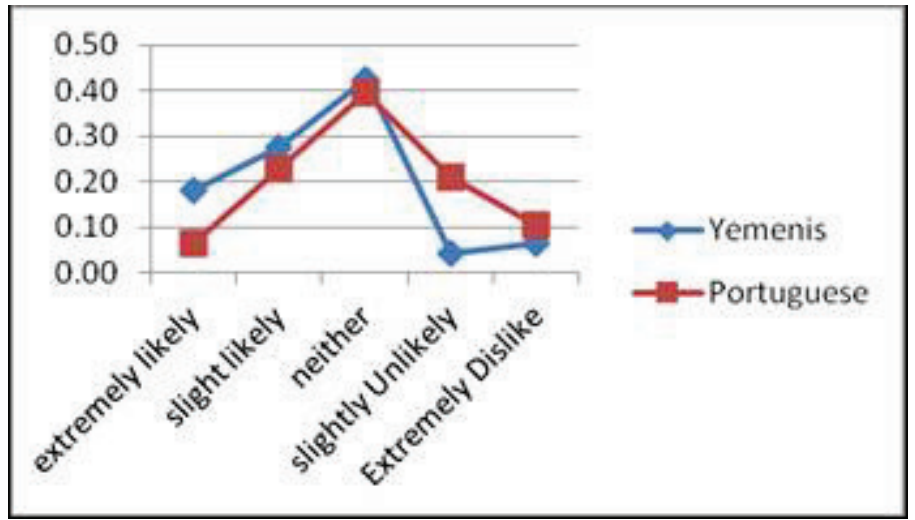

Figure 4: Odour and life performance

Concerning intention to use odour in ATM machines; 27\% of Yemenis and 43\% of Portuguese reported that they would use odour in ATM as an authentication method, if it is available. $26 \%$ of Portuguese and $33 \%$ of Yemenis reported that they would not use odour as an authentication tool. $39 \%$ of Yemenis and $31 \%$ of Portuguese did not have an opinion (see Figure 5).

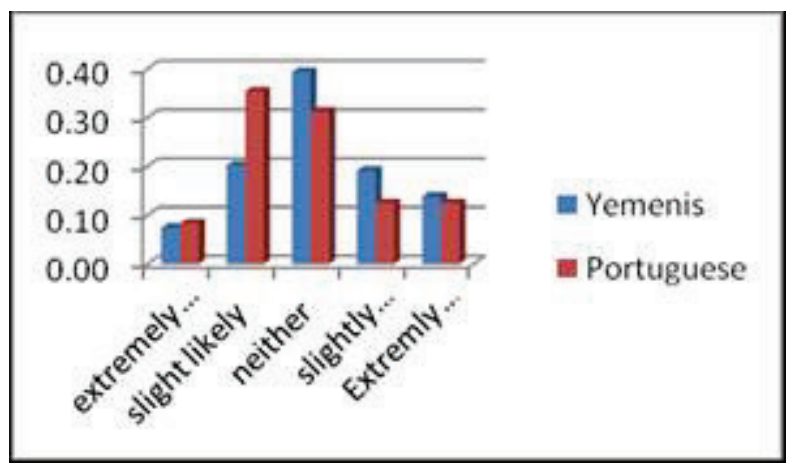

Figure 5: Intention of use

$45 \%$ of the Portuguese and $21 \%$ of Yemenis respondents reported that they liked the idea and $27 \%$ of Portuguese and $54 \%$ of Yemenis did not like the idea. $26 \%$ of Yemenis and $27 \%$ of Portuguese did not have an opinion (see Figures 6 and 7). 


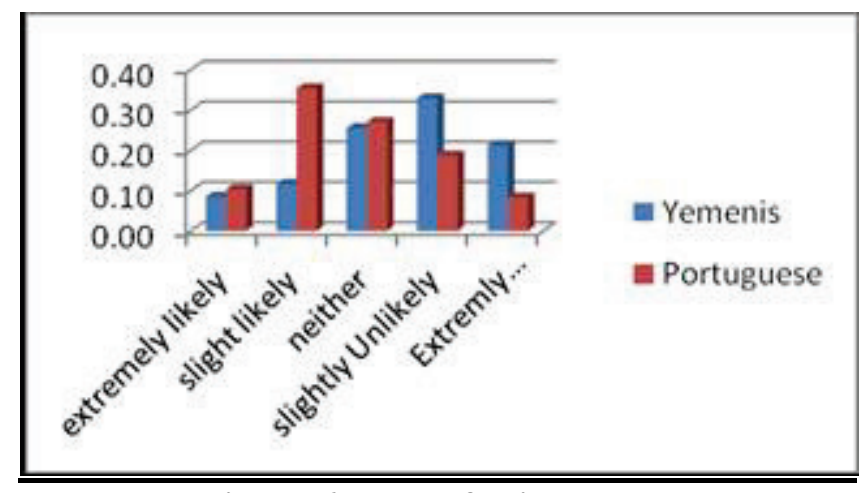

Figure 6: Idea of using odour

\begin{tabular}{|l|c|c|}
\hline & \multicolumn{2}{|c|}{ Standard Deviation } \\
\hline & Yemenis & Portuguese \\
\hline Perceive ease of use & 0.76 & 0.13 \\
\hline Perceive usefulness & 0.16 & 0.13 \\
\hline Intention to use & 0.11 & 0.12 \\
\hline
\end{tabular}

Figure 7: Descriptive Analysis

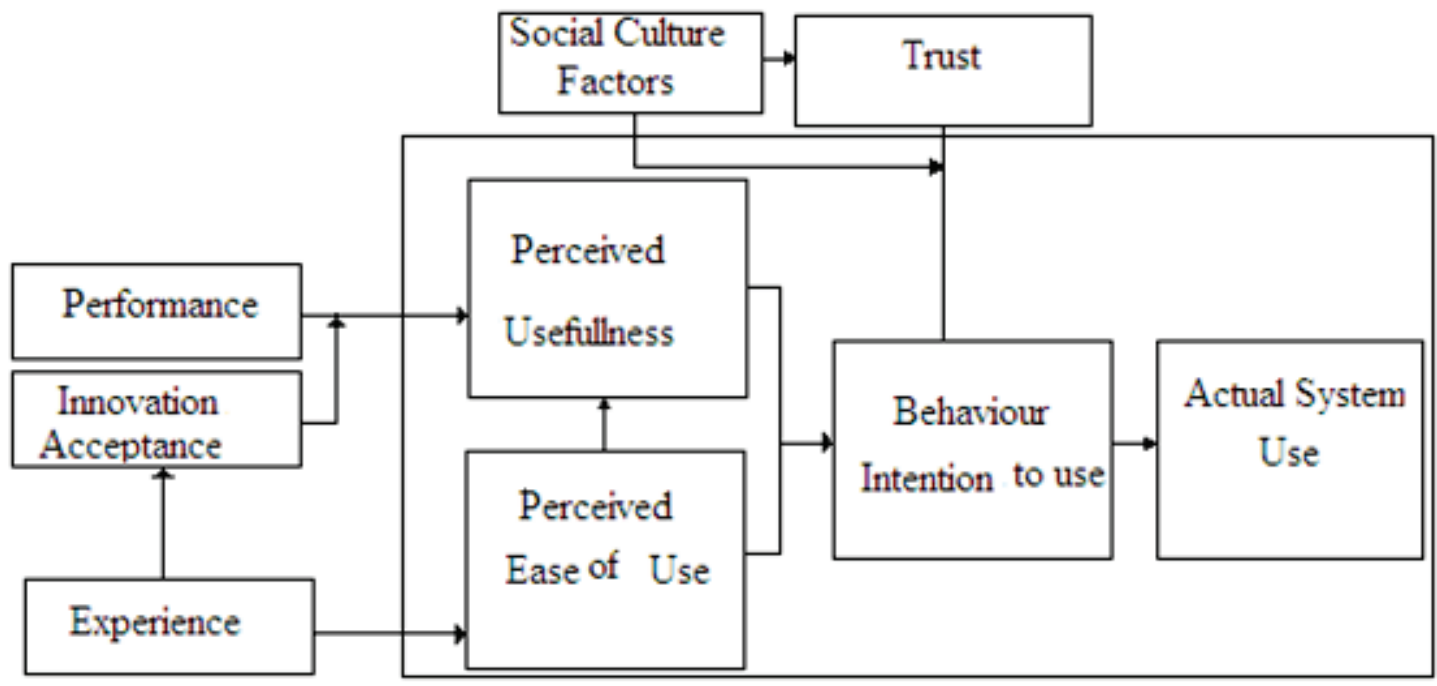

Figure 8: Proposed Model

Figure 8 shows that security issues should be embedded within any technology acceptance model. We believe that perceive usefulness depends on the perceived performance innovation and experience.

\section{Conclusion}

Yemenis perceived the ease of use and perceived usefulness more than Portuguese. However, Portuguese showed more receptive to new technologies. Portuguese showed more consistency in correlation between the perceived usefulness and ease of use, and intention to use. Finally, Portuguese group in their comments showed more worries about risk that might affect the users; security is still the first issue for the users, so we suggest adding user concerns to the model. The reason is that user would prefer difficult tool if it is secure. 


\section{Acknowledgement}

This work was funded by FEDER through Programa Operacional Fatores de Competitividade COMPETE, and by national founds through FCT - Fundação para a Ciência e Tecnologia, under project: FCOMP-01-0124-FEDER-022674.

\section{References}

Beekhuyzen, J., Hellens, L., \& Siedle, M. (2005). Cultural barriers in the adoption of emerging technologies. Proceedings of HCI International 2005.

Coventry, L. (2004). Biometrics, self-service and the user. Biometric Technology Today, November/December, 7-9,

Belshek, J. (2006). The influence of culture on the negotiation styles of British students. Annual Review of Education, Communication, and Language Sciences, 3.

Barati, S., \& Mohammadi, S. (2009). An efficient model to improve customer acceptance of mobile banking. Proceedings of the World Congress on Engineering and Computer Science 2009 Vol. II WCECS 2009, October 20-22, 2009, San Francisco, USA.

Dhamija, R., \& Perrig A. (2000). D'ej 'a Vu: A user study using images for authentication. 9th USENIX Security Symposium, Denver, Colorado, US.: 4 - 4.

Genkova, P. (2009). Subjective theory: A culture comparison concerning well-being. US-China Education Review, 6(10), (Serial No.59).

Johnston, K., \& Johal, P. (1999). The internet as a "virtual cultural region": Are extant cultural classification schemes appropriate? Journal of Internet Research, 9(3),178 - 186.

Kersten G. E. (2011). available via http://interneg.carleton.ca/ gregory/

Kripanont, N. (2007). Examining a technology acceptance model of internet usage by academics within Thai business schools. PhD thesis, School of Information Systems, Faculty of Business and Law, Victoria University, Melbourne, Australia. Available at http://vuir.vu.edu.au/1512/1/Kripanont.pdf

Mao, E., \& Palvia, P. (2006). Testing an extended model of IT acceptance in the Chinese cultural context. ACM SIGMIS Database, 37(Issue 2-3) (Spring-Summer, SESSION: Research contributions), 20-32.

McIntosh, D. (2009). Biometrics - a fad or the future? Biometric Technology Today, 9-11.

Myers, M., \& Tan F. (2002). Beyond models of national culture in information systems research. Journal of Global Information Management, 10(2). Idea Group Publishing.

Quaddus, M., \& Tung, L. L. (2002). Explaining cultural differences. Communications of the ACM, 45(8), 93-98.

Ramayah, T., Chin, Y. L., Norazah, M., \& Amlus, I. (2005). Determinants of intention to use an online bill payment system among MBA Students. E-Business, 9, 80-91.

Rashed, A., \& Santos, H. (2010a). Odour user interface for authentication: Possibility and acceptance: Case study. The International MultiConference of Engineers and Computer Scientists 2010 (IMECS2010), (The 2010 IAENG International Conference on Bioinformatics), Hong Kong.

Rashed, A., \& Santos, H. (2010b). OTM machine acceptance: in the Arab culture. ICGS3 6th International Conference for on Global Security, Safety and Sustainability, 1-3 September 2010, Braga, Portugal.

Rose, G., \& Straub, D. (1998). Predicting general IT use: Applying TAM to the Arab world. Journal of Global Information Management, 6(3), 39-46.

Samarah, I., Paul, S., \& Mykytyn, P. (2002). Exploring the links between cultural diversity, the collaborative conflict management style, and performance of global virtual teams. Eighth Americas Conference on Information Systems 2002. 
Tibenderana, P., \& Ogao P. (2008). Acceptance and use of electronic library services in Ugandan universities. International Conference on Digital Libraries, Proceedings of the 8th ACM/IEEE-CS joint conference on Digital libraries, Pittsburgh PA, PA, USA.

Triandis, H. (1994). Theoretical and methodological approaches to the study of collectivism and individualism. In U. Kim, H. C. Triandis, C. Kagitcibasi, S. C. Choi \& G. Yoon (Eds.), Individualism and collectivism: Theory, method, and applications (pp. 41-51).

Twati, J. (2009). Societal and organisational culture and the adoption of management information systems in Arab Countries. Ph.D. Thesis, Griffith University.

Yeo, A. (1996). Cultural user interfaces. A silver lining in cultural diversity. SIGCHI Bulletin 3, 4-7

\section{Biographies}

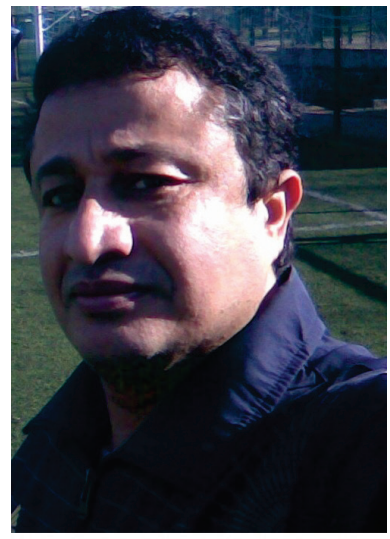

Abdullah A. Rashed is an assistant professor. He obtained his Ph.D. in 2004 in computer information systems and his masters in information systems in 2000 and his BSc in computer sciences in 1997. His main interest is user perception of new technologies. Now, he is with the Research Centre Algoritmi, University of Minho, Portugal (e-mail: abdullahrashed@yahoo.com).

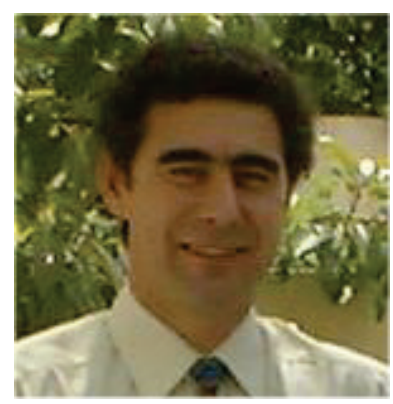

Henrique M. Dinis Santos received his first degree in Electric and Electronic Engineering, by the University of Coimbra, Portugal, in 1984. In 1996 he got his PhD in Computer Engineering, at the University of the Minho, Portugal. Currently he is an Associate Professor at the Information Systems Department, University of Minho. He is also the president of a national Technical Committee (CT 136) for information system security standards. 